\title{
Application of Magnesium Alloys in Transport
}

\author{
W. A. Monteiro12, S. J. Buso3 and L. V. da Silva1 \\ Additional information is available at the end of the chapter \\ http://dx.doi.org/10.5772/48273
}

\section{Introduction}

Magnesium alloys have always been attractive to designers due to their low density, only two thirds that of aluminum alloys in the aerospace industry and therefore can be an innovation technology if used for low weight airframe structures. This has been a major factor in the widespread use of magnesium alloy castings and wrought products.

New light materials are currently inserted in world strategies of transport vehicle industry since the environment necessities for pollution and reduction of fuel consumption. Therefore the industry takes part of the risk of development of such alloys but, in fact, some of this has been made at academic level. Some aspects of the necessities and characteristics concerning those alloys are: low costs, insulation (sound and thermal), impact safety, deformation strength, recyclability and guarantee (to aging as example). All those aspects are linked with the increasing of new vehicle models and reflect in production programs that are more and more complexes (Raynor, 1959; Roberts, 1960; Eliezer et al, 1998).

However to use this low weight material several mechanical properties have to be increased and the technological behavior improved. A further requirement in recent years has been for superior corrosion performance and dramatic improvements have been demonstrated for new magnesium alloys. Improvements in mechanical properties and corrosion resistance have led to greater interest in magnesium alloys for aerospace and specialty applications.

Magnesium alloys are also used in many other engineering applications where having light weight is a significant advantage. Magnesium-zirconium-aluminum alloys tend to be used in relatively low volume applications where they are processed by sand or investment casting, or wrought products by extrusion or forging.

Actually it's well known that there are a growth in primary production of magnesium due to a supplementary application of your products in market. A total 2010 production of pri- 
mary magnesium in the world was approximately 809,000 tons. The main producer are China 654,000 tons, USA 45,000 tons, Russia 40,000 tons, Israel 30,000 tons, Kazakhstan 20,000 tons and Brazil 16,000 tons (China Magnesium Association; U. S. Geological Survey).

\section{Magnesium alloys for transport applications}

The automobile have more than a hundred years since its invention and the light alloys have been utilized since 1915. In the 30's the aluminum did substitute almost completely the casting iron as main component of pistons. In the same decade, in Germany, magnesium alloys were utilized in the production of camshaft and in the gear box, which leads, at that time, the total decrease of weight at least $7 \%$ of the total of the automobile.

Magnesium alloy developments have traditionally been driven by aerospace industry requirements for lightweight materials to operate under increasingly demanding conditions. In the last decade several heavy magnesium parts have been assembled in passenger cars, such as gear box housings and crank cases (Aghion, 2003).

Considerable research is still needed on magnesium processing, alloy development, joining, surface treatment, corrosion resistance, and mechanical properties improvement. Surface coatings produced for magnesium die-casting by hexavalent chromium baths have been used to provide stand-alone protection and as a pretreatment for painting. Teflon resin coating has been developed for Mg alloys; initially the coating is obtained with an aluminum vapor deposition and finish treatment with a Teflon resin coating. The Teflon resin coating is a low cost, chromium-free corrosion resistant coating for magnesium alloys. The coating not only has corrosion resistant properties, but also good lubricity, high frictional-resistance and non-wetting properties (Kulekci, 2008).

These new projects are concerned on the modification of existing and the development of new magnesium wrought products (sheets and extrusions), that provide significantly improved static and fatigue strength properties for lightweight fuselage applications (Development of material models and failure criteria for the prediction of forming processes, plastic deformation and failure behavior of components; material adapted design and the evaluation of structural behavior to close the process and development chain for aeronautic components).

The specific strength properties of these innovative materials are required to be higher than AA2024 for structural applications (secondary structure) and higher than AA5083 for nonstructural applications. At the beginning of the project new alloys will be developed and experimental alloys will be tested. Appropriate manufacturing (rolling, extrusion), forming and joining technologies require development, simulation and validation for the innovative material and application (Hombergsmeier, 2011). The technological objective is a weight reduction of the fuselage structure, system and interior components up to $30 \%$. The strategic objectives are an increase in the operational capacity of $10 \%$, a reduction in the direct operating cost of $10 \%$ and finally a reduction in the fuel consumption of $10 \%$ and therefore a reduced environmental impact with regard to emissions and noise (Hombergsmeier, 2009). 
Regarding corrosion is also a problem to be solved with newly adapted surface protection systems according to aerospace requirements and advanced design concepts. The addition of chemical elements and special surface treatments in magnesium to avoid flammability (auto-ignition temperature); Mg alloys with eutectic phases, low melting temperature, ignite first with comparative investigations to aluminum alloys (Hombergsmeier, 2011).

For those purposes there are nowadays some new techniques for the production of this kind of light alloys, notably: powder metallurgy (PM), which is essentially the process that leads small particles (from sizes in a range from nanometers to tens of micrometers) to a consolidation process that results in a uniform and fine grained structure material; spray forming techniques that relies in production processes which allows the production of parts and components by deposition of sprayed particles in semi-molten state that will consolidate in an injection mold with a substrate and metal foam. In addition the nanostructured materials have been the utmost in materials development due mainly to their particular relationship between microstructure of grains or hyperfine particles and mechanical properties, differentiated from those produced by conventional processes.

The development of solid state powder metallurgy makes it possible to increase the values of solute above the limits of conventional metallurgy arising a new era for the magnesium and aluminum alloys. Increasing the amount of "thirds" alloying elements gives to these alloys new characteristics such as high deformation rates at room temperature, refinement of microstructure (hyperfine grains or nanostructured materials), new conditions for cold and hot work processing, welding, wear resistance, increase of hardness as examples.

Also, recyclability of magnesium and aluminum alloys is a growing factor in choice for utilization in automotive industry, since nowadays it's possible to recycle up to $99 \%$ of parts and pieces made of magnesium and aluminum which reduces the costs with transportation and this is also good for the environment.

News production technologies search for minimize the quantities of energy employed in its processes and the recyclability shows an economy of $95 \%$ of energy comparing to that produce primary magnesium and aluminum generating an "ecological compensation".

Another influence in research for new technologies of materials and light alloys relies on the shortening of life of models. New materials and alloys are usually more expensive than commercial materials, so there is direct needs of investment in reduce the costs of production and development of such alloys allowing the utilization in large scale in the automobile production processes.

Despite the fact that the introduction of light alloys and new technology light alloys is a tendency not changeable, the utilization effective today still is more applicable to competition or sportive cars and motorcycles, due to the high costs previously mentioned. However if compared along the existence of automobile the employment of light alloys rise exponentially from the earliest up to the latest commercial model. The influence of 1970's in the development of such technologies is notable comparing with the few kilograms used in the first automobiles. All those factors contribute to new researches and development of this class of materials for structural and mechanical applications in automotive industry (transport). 
Global effort in magnesium materials development has diversified in recent years, targeting new automotive, aerospace, and also in biomedical applications. The 1990s saw a strenuous effort in the tissue to regenerate without the use of a second surgery to remove the repair implant. Research in this field is focusing on the development of new magnesium alloys with low rates of bio-degradation. Emerging areas of application for magnesium are the input for global effort in magnesium materials development. Interdisciplinary and international collaborations will be the key in developing magnesium to its full potential as an environmentally friendly structural material with wide-ranging applications (Beals et al., 2007).

A very interesting program to benefit the magnesium utilization is MagForming, an international project (12 different partners) with the aim to advance the state of the art in forming methods for a range magnesium alloys in extruded, sheet and plate forms using aerospace prototypes. This includes forging, superplastic forming, roll bending, pad forming, deep drawing and creep forming. The project aims to develop best practices for all of these methods via production of aerospace prototype parts. The data results in production of useful parts for testing, potentially leading to the use of magnesium in the system and structure areas from which the parts have been taken (Davis et al., 2009).

As mention earlier, magnesium alloys had been widely used in aircrafts up to the 1950s. Due to some major drawbacks such as high corrosion sensitivity and, under extreme conditions, flammability other materials, both metals and plastics, have increasingly replaced magnesium. Airbus is now reappraising the introduction of magnesium alloys in aircraft based on the results of recent research projects that suggest some promising applications for different alloys and product forms. Additionally Airbus is developing and investigating approaches for a lab scale fire testing procedure with the scope to ensure compliance with FAA-regulations on aircraft fire safety (Knüwer at al. 2009).

\section{The future of light alloys application including environment aspects}

New energies that will substitute the mineral energy font (petroleum) and also nowadays the increasing emission of $\mathrm{CO}_{2}$ in the entire world in the last decades lead to a special condition. So new regulations attempt to control or reduce emission and consumption has been created all over the world. In Europe the requirements also faced the reduction of production and maintenance costs and enhance the lifetime and reliability of automobile. All these conditions bring a wide field of possibilities for light alloys and new processes of production (Ditze, 1999; Kimura, 2002; Scharf, 2004).

Utilization of light alloys has as main advantages their lightness, this characteristic applied to the transport industry is related directly to the decrease of the pollution by gas emission. Some studies appointed that the reduction of $100 \mathrm{~kg}$ in net load lead to a mean reduction of combustible of 0.5 liter $/ 100 \mathrm{~km}$ and $2000 \mathrm{~kg}$ less of $\mathrm{CO}_{2}$ production during the mean life of the automobile. The increases in uses of light alloys in parts of automobiles make it much more efficient today if compared with those of the decade of 1970. 
Production and application technologies must be cost effective for magnesium alloys to make magnesium alloys an economically viable alternative for the automotive industry. At moment, the energy consumption in light alloys processes production is equivalent to steel or iron alloys.

Close to eighty percent of total energy amount used in processing production of metals were dedicated only for aluminum, iron, copper, zinc and titanium since the mining to the final alloys. A good comparison is when including light alloys recycling process where a necessity of only fifth percent of necessary energy is applied (preservation of mineral).

The environmental benefits provided by lightweight, unlimited, and recyclable $\mathrm{Mg}$ alloy have the potential to grow significantly in the future if the global $\mathrm{Mg}$ industry is working together to demonstrate its stewardship by eliminating global warming $\mathrm{SF}_{6}$ or other protective gases as well as Be addition not only for environment and toxicity issues but also for the synergy of cast shop infrastructure with $\mathrm{Al}$ industry and by ensuring safety during manufacturing and application, especially without sacrificing process abilities and mechanical properties or increasing the cost of Mg alloy (Kim et al., 2009).

A matrix of potential recycling alloys has been set up to find a potential system for the recycling of heat resistant magnesium alloys. The matrix was processed via permanent mould casting. With the development of new heat resistant magnesium alloys, the automotive industry has introduced several parts to the drive train. The rising number of large magnesium components will result in a higher quantity of automotive post consumer scrap. A matrix of potential recycling alloys based on the $\mathrm{Mg}-4.97 \mathrm{Al}-0.3 \mathrm{Mn}$ alloy was prepared via permanent mould casting (Fechner, 2009).

The magnesium die casting is a production process which is used for many years for the serial production of different products. The technology used for that has been developed considerably further in the last years. Today the die casting process is a production process with a high grade of automation. Following the state of the art is explained, to describe with it the room for improvement with regard to environment, energy consumption and safety in the process guidance. The described technology allows new procedures so that efficiency and productivity of the die casting process increase. Results are shown by means of some examples, especially in the application of high-grade and thin-walled magnesium die casting (Erhard and Schlotterbeck, 2009).

Therefore the amount of weight of light alloys in transport vehicles which that will need more primary resources could be reduced and all the parts of the environment that would be preserved to the future is huge. At moment only $30 \%$ of recycled materials can be used in automotive industry. Notwithstanding of this, the industry announces that more than ninety percent of the vehicle can be recycled today. An environmental problem in automotive industry is the actual life cycle of a vehicle, today is near 3 years.

As mentioned before environmental conservation is one of the principal reasons for the focus of attention on magnesium to provide vehicle weight reduction, $\mathrm{CO}_{2}$ emission and fuel economy. Weight reduction through $\mathrm{Mg}$ applications in the automotive industry is the effective option for decreasing fuel consumption and $\mathrm{CO}_{2}$ emissions. Improvements in $\mathrm{Mg}$ alloy- 
ing and processing techniques will make it possible for the automotive industry to manufacture lighter, more environmentally friendly, safer and cheaper cars.

Significant research is still desirable on magnesium processing, alloy development, joining, surface treatment, corrosion resistance and mechanical properties improvement to realize future targets to reduce the vehicle mass and the amount of greenhouse gases.

\section{Comparative and effective use of new Mg alloys}

New light materials are effectively nowadays inserted in world strategies of automotive industry since the environment necessities for pollution and reduction of fuel consumption. Therefore the industry takes part of the risk of development of such alloys but, in fact, some of this has been made at academic level. It's possible to enumerate some aspects of the necessities and characteristics concerning those alloys: low costs, insulation (sound and thermal), impact safety, deformation strength, recyclability and guaranty (to aging as example). All those aspects are linked with the increasing of new automobile models and reflect in production programs more and more complexes.

Different joining techniques were applied to magnesium wrought semi-finished products, in order to promote their introduction on aeronautical structures. Airbus has performed some first tests to join magnesium sheets by friction stir welding. In general the alloy AZ31B (Mg-3.0\%Al-0.3\%Mn) is quite easily weldable by different processes. Using laser beam welding an AZ61 (Mg-5.9\%Al-0.5\%Zn-0.2\%Mn) filler wire is advantageous for the mechanical properties to weld this alloy.

Another influence in research for new technologies of materials and light alloys relies on the shortening of models life. New materials and alloys are usually more expensive than commercial materials, so there is direct needs of investment in reduce the costs of production and development of such alloys allowing the utilization in large scale in the automobile production processes.

The increase in the potential application of magnesium profiles is strongly dependent on the question of whether established forming processes for aluminum and steel can be changed to magnesium and its alloys. Broad-spectrum applications of magnesium alloys in the automotive industry are casting products.

Despite the fact that the introduction of light alloys and new technology light alloys is a tendency not changeable, the utilization effective today still is more applicable to competition or sportive cars and motorcycles, due to the high costs previously mentioned. However if compared along the existence of automobile the employment of light alloys rise exponentially from the earliest up to the latest commercial model. The influence of 1970's in the development of such technologies is notable comparing with the few kilograms used in the first automobiles.

Recently the weightiness of light alloys, for example, in an automobile is near $90 \mathrm{~kg}$ in Europe, $120 \mathrm{Kg}$ in United States and $42 \mathrm{~kg}$ in Brazil, but increasing year-to-year. Nearly $90 \%$ or 
more from the weight relies on aluminum alloys, but there is a rapidly increase in the magnesium and a slightly in titanium alloys in the total amount used. All those factors contribute to new researches and development of this class of materials for structural and mechanical applications in automotive industry.

Traditionally the main usage for magnesium and magnesium alloys has been for aluminum alloying, high pressure die casting and steel desulphurization. Over the last 10 years the demand for magnesium and its alloys has grown at an average rate close to $5 \%$ per year. The die casting industry which expanded at a rate of over $10 \%$ per year was mainly responsible for this steady growth of the whole industry. This remarkable growth was possible because of the stable and relatively inexpensive supply of magnesium from China. This low costs supply has changed at the end of 2007 and early 2008. During that period the base price of magnesium has tripled. In this article present and future opportunity in supply and demand of magnesium and magnesium alloys are examined. Special attention will be given to the growth potential of magnesium alloys for components which will be driven most likely by environmental regulations from governments (Closset, 2008)

As the lightest structural materials, magnesium alloys are well suited for the car industry and also good fuel economy is essential. The selection of a new alloy for a vehicle component should be based on technical requirements and targeted cost. In reality, this selection process is complicated and depends very much on the relative weight given to a specific property, which is part of the combined desired properties and final targeted cost. This task becomes even more complicated if alternative material systems such as aluminum alloys are considered for the same applications.

Several new magnesium alloys have been developed recently for high temperature applications to obtain an optimal combination of die castability, creep resistance, mechanical properties, corrosion performance, and affordability. Most of the new alloys can only partially meet the required performance and cost. The ZE41 alloy (gravity-casting applications) has moderate strength and creep resistance combined with good castability. Although this alloy exhibits poor corrosion resistance, it is still preferred for certain applications.

Although the most commonly used magnesium die-casting alloys are of the AZ and AM series, improved elevated-temperature performance is required (gearbox housing, intake manifolds, oil pans, transfer cases, crankcases, oil pump housing). Insufficient creep strength of alloys can causes poor bearing-housing contact, leading to oil leaks and increased noise and vibration.

The use of magnesium alloy casting in the automobile industry expands at an impressive rate in this decade, which can manage with the energy and environment problems. Alloy AZ91 (Mg-9Al-0.8Zn-0.2Mn) is the most favored magnesium alloy, being used in approximately $90 \%$ of all magnesium cast products (Guangyina et al., 2000).

There are two patented magnesium alloys (Dead Sea Magnesium Ltd, 2012): Mg-Al-Ca-Sr based alloy (MRI 153M) and Mg-Al-Ca-Sr-Sn based alloy (MRI 230D). The MRI 153M is a beryllium-free, creep-resistant alloy capable of long operation at temperatures up to $150^{\circ} \mathrm{C}$ under high stresses (substantially superior to those of commercial alloys). The MRI 230D is a 
die-casting alloy developed for use in automotive engine blocks operating at temperatures up to $190^{\circ} \mathrm{C}$. The alloy has excellent creep resistance combined with good castability, high strength, and superior corrosion behavior. The results obtained show that MRI 230D and A380 exhibit similar tensile creep behavior at $150-175^{\circ} \mathrm{C}$ under stress of $70 \mathrm{MPa}$ (Aghion, 2003).

Concerning the whole aeronautic industry, due to the fact that weight reduction is a very important objective for strengthening the competitiveness, several alternatives to obtain weight reduction has to be investigated (welded or bonded airframes; use of metal laminates; structural plastics; fiber reinforced composites).

The non-metallic materials application in selected areas is not conceivable due to restricted properties under low or elevated temperatures, missing electrical conductivity or low damage acceptance. Fiber reinforced plastics are a relatively lavish material only used for primary structure applications with highest demands.

The family of magnesium alloys and especially magnesium wrought materials can be an excellent alternative because of their low density, good mechanical properties, moderate cost and metallic character (in respect of manufacturing, repair, maintenance compared to composites).

In the past decade a lot of research activities and development projects have been carried out working on magnesium cast materials mainly for transport applications. There were only very few activities on magnesium wrought products like sheets, extrusions or forged parts. The alloy spectrum of magnesium wrought alloys is still very restricted.

Aeronautic requirements and applications of wrought products have been evaluated only in a few projects. Increasing the research on magnesium wrought alloys will promote a new class of metallic materials for aeronautical applications to win the competition against plastics and fiber reinforced plastics. Therefore, the variety of offered metallic materials will be enlarged, not only for aircrafts, but also for space, military and satellites applications.

To reach this objective magnesium has to deliver meaningfully higher weight specific mechanical properties compared to aluminum. The aims for aluminum replacement can be divided into two different steps in respect of time scale and risk.

A replacement of medium strength 5XXX aluminum alloys for cockpit and cabin applications and another possible replacement of medium to high strength $2 \mathrm{XXX}$ aluminum alloys for secondary structure or non-pressurized fuselage applications.

Forming and joining technologies require development, simulation and validation for the innovative material and technologies commonly used within aeronautic industry. Recently Hombergsmeier presented the requirements of new alloys concerning property temperature systems and structural applications (see Table 1).

\begin{tabular}{|l|c|c|}
\hline Properties & $T(K)$ & Materials \\
\cline { 2 - 2 }
\end{tabular}




\begin{tabular}{|l|c|c|c|}
\cline { 3 - 4 } & & $\begin{array}{c}\text { Structural } \\
\text { applications }\end{array}$ & Systems applications \\
\hline Tensile Ultimate Strength & RT & $450 \mathrm{Mpa}$ & $275-350 \mathrm{MPa}$ \\
\hline Tensile Yield Strength & RT & $350 \mathrm{Mpa}$ & $200-300 \mathrm{MPa}$ \\
\hline Elongation to fracture & RT & $16-18 \%$ & $12-16 \%$ \\
\hline Yield Strength & 423 & 0.9 YTS & 0.9 YTS \\
\hline Compressive Yield Strength & RT & 1.1 YTS to 0.9 YTS & 1.1 YTS to 0.9 YTS \\
\hline Failure under compression & RT & alike: Al 2024 T3 & alike: Al 5083 \\
\hline Specific Weight & RT & 1.75 & 1.75 \\
\hline Residual Strength & RT & alike to 2024 T3 & n. a. \\
\hline Fatigue Crack Growth & RT & alike to 2024 T3 & n. a. \\
\hline Fatigue Limit (K $=1.0$, R=0.1) & RT & 140 Mpa & 160 MPa \\
\hline
\end{tabular}

Table 1. Requirements for Mg alloys for transport applications (Hombergsmeier, 2009)

The most promising new alloy systems selected due to corrosion behavior, green friendliness and mechanical performance for further investigation as wrought products were $\mathrm{Mg}$ Al-Zn, Mg-Zn-Zr-Re and Mg-Y-Re (Hombergsmeier, 2009, 2011). An undertaking processing for magnesium alloys is the application of severe plastic deformation (SPD) that makes available a useful tool for introducing very significant grain refinement in bulk metallic materials. Even though several SPD techniques are now accessible, processing by equalchannel angular pressing (ECAP) is especially attractive because it is easily scaled-up for use with large samples. Since grain refinement is generally believed to have beneficial effect on properties of $\mathrm{Mg}$ alloys, fabrication of bulk ultrafine-grained (grain size less than $1 \mu \mathrm{m}$ ) alloys using the new conceptual metal forming process (SPD) should attract considerable attention (Lowe and Zhu, 2003; Valiev, 2004; Figueiredo and Langdon, 2009; Jiang and Ma, 2011).

\section{Magnesium alloys for cycle applications}

Bicycle frames have gone from wood to steel to advanced alloys to composites in the last century and a half. Bikes themselves have gone from simple curiosities to serious modes of transportation in developing countries and a major form of sports and recreation in developed ones. The improvements in automotive and aerospace industry are now helping to increase a rebirth in the bicycle industry. Similarly, mass production techniques derived for the automotive industry have helped bring the cost down but, many of the original materials and production processes used today remain unchanged from over a hundred years ago (Brower, 2005). 
The basic properties of magnesium alloys propose that they would keenly find use in bicycles. Magnesium alloys have low density and a high strength to-weight ratio, are readily extrudable, and some alloys are highly weldable. A lack of information about wrought magnesium alloys, a lack of suppliers to complete the production process, and a lack of information in how to set up a mechanized plant to process wrought magnesium alloys have contributed to only limited market dissemination by magnesium into bicycle applications (Deetz, 2005).

Many doubts limit the recognition of welded magnesium alloy tubes as a substitute bicycle frame material. Most bicycle industry believes that magnesium is not weldable and is very brittle. But some alloys are weldable and it has been recognized that the ductilities of common magnesium alloys (Avadesian, 1999) are equivalent to aluminum alloys, for example, 6061 and 7075 aluminum alloys.

A common misunderstanding is related to wellbeing, with a conviction that contact with oxygen or water will cause explosions. Also that magnesium alloys lack sufficient stiffness to make a bicycle frame. Actually start the acceptance larger diameters to compensate lower stiffness and tensile strength. Concerning the difference between the Young modulus of aluminum and magnesium is much less than the difference between steel and aluminum. With applied basic design principles, it is assumed that the general requirement for product improvements will press on bicycle manufacturers to more seriously consider wrought magnesium as an attractive alternative to the utilized common materials (steel, aluminum, carbon fiber composites).

Magnesium frames may be manufactured by die casting or by welding extruded and welded tubes. Die-casting requires the recovery of die costs that is expensive, but cast magnesium can offer economy with large production volumes. So a manufacturing route could offer a low-cost transportation solution for a developing country.

The wrought magnesium alloys generally offer improved elongation and superior forms. Wrought tubes formed and bent into frame tubes represent a highly flexible and economical approach. Also the weldability rates of magnesium alloys are generally higher than competing aluminum or titanium alloys, or even alloy steels (Welding is the primary method of joining planned for magnesium alloys. His efficiency is very high and many Mg alloys not require post heat treatment).

Among the high damping properties and low density of magnesium it can easily exceed any of the current metals in ride quality leading to an improved fatigue life. Extruded profile designs need to reduce weight and maintain dent resistance in specific key functional areas. Magnesium alloys have a range of potential benefits to offer the bicycle designer, ranging from low density, high specific strength, and dent resistance to extrudability, machinability, and weldability. Finally, making bicycles that win races is the key to providing magnesium a lasting foothold in the cycle industry.

In other areas of the bicycle, rims have been made using Elektron ZM21 and AZ61. Pedals and handlebar stems have also been developed. Wheel hubs, seat posts, brakes, cranks, and ven forks have been produced by companies that specialize in industrialization of high- 
quality products. Clearly, pioneering an entire class of metal was not well suited to replacement strategy or ad-hoc engineering. Most of the initial efforts have not been successful because rushed planning combined with limited infrastructure ultimately led to problems (Deetz, 1999; Easton et al., 2008, Ashby, 2003).

\section{Conclusion}

Magnesium has a number of qualities and scantnesses compared to the others lightweight metals. There are a number of developments occurring in the magnesium improvement which promise fine for the future. In the science fundaments there is consciousness that to see the greatest utilization of magnesium both cast and cast and wrought and an adequate scientific foundation is required including new development of deformation behavior in processing to obtain desired microstructures (corresponding good mechanical properties) and near-net shapes (to reduce machining employment); also better phase transformations understanding to allow development of new cast and wrought alloys. The very low density of magnesium together with attractive features like castability is leading to an expanded transport market. Increased use can come from an expanded design base; better understanding of the fundamentals of magnesium behavior and development of cost-affordable cast and wrought alloys.

\section{Acknowledgement}

The authors would like to acknowledge the financial support of IPEN; UPM; CNPq and CAPES (Brazilian government fellowships).

\section{Author details}

W. A. Monteiro ${ }^{1,2}$, S. J. Buso ${ }^{3}$ and L. V. da Silva ${ }^{1}$

Materials Science and Technology Center - IPEN, São Paulo,, Brazil

School of Engineering - Presbyterian Mackenzie University, São Paulo,, Brazil

Uni - Santana, São Paulo,, Brazil

\section{References}

[1] Aghion, E., Bronfin, B., \& Von, Buch. F. (2003). Newly developed magnesium alloys for powertrain applications. . Journal of Metals, 55, 2003, ., 11, 30-33. 
[2] Avadesian, M. M., Baker, Hugh., \& (editors, . (1999). Magnesium and Magnesium Alloys, ASM Specialty Handbook (Materials Park, OH: ASM International), , 17.

[3] Ashby, M., \& Johnson, K. (2003). "The Bicycle: Materials and Form”, in: Materials and D. esign: The Art and Science of Material Selection in Product Design, Butterworth \& Heinemann, ., 108-109.

[4] Beals, R. S., Tissington, C., Zhang, X., Kainer, K., Petrillo, J., Verbrugge, M., \& Pekguleryuz, M. (2007). Magnesium Global Development: Outcomes from the TMS 2007 Annual Meeting. , Journal of Metals, ., 39-42.

[5] Brower, M. (2005). Advancements in Materials Used in Bicycle Frames, Term Paper, (Materials Science and Engineering- EGR250, Instructor: Dr. P. N. Anyalebechi), School of Engineering, Grand Valley State University.

[6] Closset B. (2008). Supply and Demand Developments in the Magnesium Industry, Proc. 16th Magnesium Automotive and User Seminar, 18-19 September 2008, Aalen University, Germany.

[7] Davis, B., Wilks, T., Fein, A., Hombergsmeier, E., \& Entelmann, W. (2009). MagForming- Development of New Magnesium Forming Technologies for the Aeronautics Industry. Proceedings of IMA Annual World Magnesium Conference, Fremont, USA, May - June 2, 2009., 31.

[8] Dead Sea Magnesium Ltd, Magnesium alloys for high temperature applications, http://www.dsmag.co.il/?cmd=products.11, accessed (24). 24 / 03 / 2012.

[9] Deetz, J. (2005). The Use of Wrought Magnesium in Bicycles. , Journal of Metals, ., 50-53.

[10] Ditze, A. (1999). Material cycle for magnesium. . Aluminium. , 75, 157-160.

[11] Easton, M., Beer, A., Barnett, M., Davies, C., Dunlop, G., Durandet, Y., Blacket, S., Hilditch, T., \& Beggs, P. (2008). Magnesium Alloy Applications in Automotive Structures. . Journal of Metals. November 2008, 57-62., 60(11)

[12] Erhard, N., \& Schlotterbeck, M. (2009). Die Casting for the Future Economically and Ecologically. Proceedings of IMA Annual World Magnesium Conference, Fremont, USA, May - June 2, 2009., 31.

[13] Eliezer, D., Aghion, E., \& Froes, F. H. (1998). Magnesium Science, Technology and Applications, in: Adv. anced Performance Materials ., 5, 201-212.

[14] Fechner, D., Blawert, C., Hort, N., \& Kainer, K. U. (2009). Recycling of magnesium drive train components. . Science in China Series E: Technological Sciences. 2009, , 52(1), 148-154.

[15] Figueiredo, R. B., \& Langdon, T. G. (2009). Principles of grain refinement in magnesium alloys processed by equal-channel angular pressing. . J Mater Sci, 2009, , DOI 10.1007/s10853-009-3725-z, 44, 4758-4762. 
[16] Guangyina, Y., Yangshanb, S., \& Wenjianga, D. (2000). Effects of Sb addition on the microstructure and mechanical properties of AZ91 magnesium alloy. Scripta Materialia, 43, 2000, , 1009-1013.

[17] Hombergsmeier, E. (2009). AEROMAG- Magnesium for aerospace applications, in: http://www.materials.manchester.ac.uk/pdf/research/latest/magnesium/ elke_hombergsmeier_AEROMAG\%20Paper_07.pdf, (22/01/2011).

[18] Hombergsmeier, E. (2011). AEROMAG- Magnesium suitable for aeronautic applications?, Proceedings of the Sixth European Aeronautics Days- Aerodays, Madrid, March 30th to April 1st 2011

[19] Kim, S., Lee, J., Jang, D., Yoon, Y., Ha, S., Yoo, H., Park, S., Lee, C., \& Kim, Y. (2009). Eco-Mg for Magnesium Future, Proceedings of IMA Annual World Magnesium Conference, Fremont, USA, May - June 2, 2009., 31.

[20] Kimura, K., Nishii, K., \& Kwarada, M. (2002). Technology for recycling magnesium alloy housings of notebook computers. . Mater Trans, 43, 2002, , 2516-2522.

[21] Kulekci, M. K. (2008). Magnesium and its alloys applications in automotive industry. . Int. J. Adv. Manuf. Technol. 2008, , DOI 10.1007/s00170-007-1279-2, 39, 851-865.

[22] Knüwer, M., Guillan, A., Besuchet, P., Busch, H., , P., Entelmann, W., Hombergsmeier, . E., \& (2009, . (2009).Development of Magnesium Alloy Parts for Airbus Aircrafts. , Proceedings of IMA Annual World Magnesium Conference, Fremont, USA, (31). - June 2, 2009, 31.

[23] Lowe, T. C., \& Zhu, Y. T. (2003). Commercialization of nanostructured metals produced by severe plastic deformation processin. g. Adv. Eng. Mater. 2003, ., 5, 373-378.

[24] Ostrovsky, I., \& Henn, Y. (2007). Present state and future of magnesium application in Aerospace Industry, Proceedings of International Conference "New Challenges in Aeronautics", ASTEC'07, August 19-22, 2007, Moscow

[25] Raynor, C. V. (1959). The Physical Metallurgy of Magnesium and its Alloys,. Pergamon Press, London.

[26] Roberts, C. S. (1960). Magnesium and its Alloys,. Wiley, New York.

[27] Jiang, J., \& , A. (2011). Bulk Ultrafine-Grained Magnesium Alloys by SPD Processing: Technique, Microstructures and Properties, chapter 9 in: Magnesium Alloys- Design, Processing and Properties, Ed. Frank Czerwinski, InTech, 978-9-53307-520-4 187- 219, January 2011.

[28] Scharf, C., Blawert, C., \& Ditze, A. (2004). Application of remelted post consumer scrap for structural magnesium parts. Proc. of 6th International Conference Magnesium Alloys and Their Applications. Weinheim: Wiley-VCH, 2004. , 980-987. 
[29] Valiev, R. (2004). Nanostructuring of metals by severe plastic deformation for advanced properties,. Nature Materials, www.nature.com/naturematerials, August $2004, ., 3,511-516$. 